Loyalitas Kreativitas
Aldi Masyarakat Kreatif

P-ISSN 2722-2101, E-ISSN 2722-4201

Program Studi Ekonomi Manajemen Universitas Pamulang

Jurnal LOKABMAS Kreatif Vol.02,No.03.Nov 2021 Hal.74-78

Email:jurnalkreatif.manajemen@gmail.com

\title{
MANAJEMEN UPAYA MENINGKATKAN MINAT BELAJAR DAN KREATIVITAS ANAK DI MASA PANDEMI COVID-19 PADA YAYASAN ISLAM AL AKHYAR
}

\author{
Fahmi Susanti ${ }^{1}$ Armelia Oktaviani ${ }^{2}$, Dewi Kurnia ${ }^{3}$, \\ Eka Supriyanto ${ }^{4}$, Hendra Kautsar $\mathbf{R}^{5}$, Ika Safitri ${ }^{6}$ \\ Universitas Pamulang \\ Email: dosen02024@unpam.ac.id \\ dewik4971@gmail.com, raffyhendra4@gmail.com, armeliaoktaviani@gmail.com, \\ supriyekas01@gmail.com, Safitriika93@gmail.com
}

\begin{abstract}
This service is in collaboration with the Al-Akhyar. Islamic Foundation This study aims to determine the level of interest in learning and creativity of children during the COVID-19 pandemic with online or online learning models. The results of the study can be concluded, that learning in the era of the covid-19 pandemic, the level of interest in learning and creativity in the children of the Al-Akhyar Islamic Foundation has decreased. With online or online learning, it is not entirely possible for children to learn to understand from this learning. But at least learning through online or online learning can increase interest in learning and creativity in these children.
\end{abstract}

\section{Keywords: Interests in Learning, Creativity, Children}

\begin{abstract}
Pengabdian ini bekerja sama dengan Yayasan Islam Al-Akhyar ini bertujuan untuk mengetahui tingkatan minat belajar dan kreativitas anak-anak dimasa pandemi covid-19 dengan model belajar secara daring atau online. Hasil penelitian dapat disimpulkan, bahwa belajar di era pandemi covid-19 ini tingkatan minat belajar dan kreativitas pada anak-anak Yayasan Islam Al-Akhyar hasilnya menurun. Dengan adanya pembelajaran secara online atau daring memang tidak sepenuhnya anak-anak belajar bisa memahami dari pembelajaran tersebut.Namun setidaknya belajar melalui pembelajaran secara daring atau online ini bisa meningkatkan minat belajar dan kreativitas pada anak-anak tersebut.
\end{abstract}

Kata Kunci: Minat Belajar , Kreativitas , Anak-anak

\section{A. PENDAHULUAN}

Pengabdian di lakukan pada Yayasan Islam Al-Akhyar berlokasi Jl. Swadaya Raya No. 23 Beji, Kota Depok, Jawa Barat. Analisis situasi dan latar belakang pengelolaan Yayasan Islam Al-akhyar sebagai salah satu aspek penting bagi kemajuan sebuah yayasan dapat dilakukan menggunakan praktik media pembelajaran sederhana. Media pembelajaran sederhana merupakan media pembelajaran yang tidak berbasis teknologi modern dan dapat dibuat sendiri dengan relative mudah dan tidak memerlukan biaya yang mahal. Secara umum kesederhanaan itu mengacu kepada jumlah elemen yang terkandung dalam suatu visual. Untuk menghasilkan informasi media 
pembelajaran yang tidak dapat digunakan di. Banyak pengurus dan pengelola sekolah yang merasa bahwa sekolah Yayasan Islam AlAkhyar sudah berjalan normal namun sebenarnya Yayasan tersebut belum berkembang. Ketika mereka (para pengelola dan pengurus) dihadapkan pada kebutuhan mendesak misal karena adanya salah satu fasilias yang kurang, media pembelajaran yang kurang atau bahkan pertanyaaan untuk pengembangan yayasan, para pengelola mengandalkan dana sumbangan sosial dari pengurus dan masyarakat lainnya. Banyak transaksi yang terjadi di sekolah seperti SPP, uang gedung, pembelian seragam, renovasi ruang kelas, dan lain sebagainya yang dilakukan per bulan, semester dan tahun. Dilingkungan kita, terdapat banyak benda yang dapat dijadikan sebagai media pembelajaran sederhana.

Sejak masa pandemi Covid-19 berlangsung pemerintah mengambil keputusan untuk sekolah diadakan daring atau offline dengan memanfaatkan media atau aplikasi-aplikasi untuk berkomunikasi dengan guru, karena tidak adanya tatap muka tentu akan berbeda terlebih lagi untuk anakanak yang tidak terbiasa dengan keadaan tersebut tentu menimbulkan mereka malas belajar dan merasa bosan oleh karena itu kami mengadakan penengabdian untuk meningkatkan minat belajar dan kreativitas pada anak dimasa pandemi Covid-19.

\section{B. METODE PELAKSANAAN}

Kegiatan ini dilakukan melalui kerja sama dengan Yayasan Islam Al-Akhyar dengan target yakni anak-anak Yayasan Islam Al-Akhyar. Pada kegiatan ini dilakukan dengan empat tahap meliputi : tahap observasi, tahap persiapan, tahap pelaksanaan yang terbagi menjadi tahap pelatihan dan tahap pendampingan untuk menumbuhkan minat belajar pada anak-anak dan terakhir yakni tahap evaluasi. Pada tahap pelaksanaan dengan cara perkenalan secara langsung dengan anak-anak bertatap muka langsung lalu kemudian penyampaian materi dengan peralatan laptop dan memberikan motivasi serta hadiah untuk menyemangati dan membangun suasana saat tahap pelaksanaan dengan tetap mematuhi protokol kesehatan yaitu memakai masker, menjaga jarak dan menjauhi kerumunan. Dalam tahap evaluasi akan ditanyakan beberapa pertanyaan untuk mengetahui sejauh mana mereka menerima materi dan memahami yang kami sampaikan sebagai penunjang pembelajaran dimasa pandemi Covid-19.

\section{HASIL DAN PEMBAHASAN}

Pengabdian di lakukan pada yayasan Islam Al-Akhyar berlokasi Jl. Swadaya Raya No. 23 Beji, Kota Depok, Jawa Barat. Yang diselanggarakan Pada Tanggal : 15 Maret 2021. dengan tetap mematuhi protokol Kesehatan selama kegiatan pengabdian ini berlangsung Pada tanggal 15 Maret 2021 akan diadakan penyuluhan dari kegiatan Pengabdian Kepada Masyarakat oleh TimPKM dan dosen pembimbing. Materi yang akan diberikan terkait "Manajeman Upaya Meningkatkan Minat Belajar Dan Kreativitas Anak diMasa Pandemi Covid-19 Pada Yayasan Islam AL Akhyar".

Dari penyuluhan ini diharapkan dapat membantu masyarakat mengatasi persoalan dalam bersosial media. selama kegiatan pemahaman atau penyampaian materi dimaksudkan agar menumbuhkan minat belajar dan kreativitas anak-anak pada masa pandemi Covid-19, Para anak-anak juga diajarkan cara agar tidak bosan belajar serta diadakan hadiah untuk anak anak yang bisa menjawab pertanyaan-pertanyaan yang diberikan agar mereka senang. Evaluasi kegiatan akan dilaksanakan setelah pengabdian kepada masyarakat sudah terlaksana, dengan mendiskusikan kesulitan juga kekurangan yang dihadapi saat pengabdian berlangsung. Supaya bisa menjadi pembelajaran dan bahan pertimbangan dikegiatan selanjutnya.

\section{Rencana Jadwal Evaluasi}

Rencana jadwal dari awal kegiatan hingga selesai kegiatan dapat dilihat pada table dibawah ini: 
Loyalitas Kreativitas Aldi Masyarakat Kreatif
Program Studi Ekonomi Manajemen Universitas Pamulang

Jurnal LOKABMAS Kreatif Vol.02,No.02.Juli 2021 Hal.58-61

Email:jurnalkreatif.manajemen@gmail.com

\begin{tabular}{|l|l|}
\hline Waktu & Kegiatan \\
\hline $15.00-15.15$ & Pembukaan \\
\hline $15.15-15.20$ & $\begin{array}{l}\text { Perkenalan Anggota } \\
\text { Pengabdi }\end{array}$ \\
\hline $15.20-15.30$ & $\begin{array}{l}\text { Sambutan Ketua } \\
\text { Pengabdi }\end{array}$ \\
\hline $15.30-16.00$ & $\begin{array}{l}\text { Pembahasan Materi } \\
\text { dan Menonton Video }\end{array}$ \\
\hline $16.00-16.30$ & Sesi Tanya Jawab \\
\hline $16.30-16.45$ & Foto Bersama \\
\hline $16.45-17.00$ & Penutup \\
\hline
\end{tabular}

Selama kegiatan Pengabdian tersebut semua anak-anak sangat antusias. Banyak dari mereka yang senang mereka juga bersemangat untuk membaca kembali dan meningkatkan kreatifitas dimasa pandemi covid 19 meskipun pembelajaran masih akan daring namun mereka harus tetap belajar dan membaca seperti halnya yang dilakukan sekolah, mereka juga senang dengan hadiah yang diberikan karena kami mengajukan pertanyaan dan mereka berhasil menjawab, hadiah itu sangat bermanfaat untuk mereka yang masih bersekolah daring. Dan kami juga memberi sedikit materi yang berhubungan dengan Minat Membaca dan Kreativitas pada Anak.

\section{MINAT MEMBACA DAN KREATIVITAS}

(Hamdu \& Agustina,2011b) Sedangkan menurut Drs. Dimyati Mahmud (1982), Minat adalah sebagai sebab yaitu kekuatan pendorong yang memaksa seseorang menaruh perhatian pada orang situasi atau aktifitas tertentu dan bukan pada yang lain, atau minat sebagai akibat yaitu pengalaman efektif yang distimular oleh hadirnya seseorang atau sesuatu obyek, atau karena berpartisipasi dalam suatu aktifitas.

Belajar adalah suatu aktifitas dimana terdapat sebuah proses dari tidak tahu menjadi tahu, tidak mengerti menjadi mengerti, tidak bisa menjadi bisa untuk mencapai hasil yang optimal (Rauf, 2013). Minat baca dapat ditumbuhkan dan dikembangkan, sehingga menjadi kebiasaan melalui penguasaan teknik membaca yang tepat. Teknik membaca yang tepat dapat membuat membaca lebih efisien, efektif, serta menarik (Mardika, 2008). Tujuan dari pengembangan minat baca ini antara lain untuk :

1. Mendorong minat dan kebiasaan membaca agar tercipta masyarakat yang berbudaya membaca.

2. Meningkatkan layanan perpustakaan.

3. Menciptakan masyarakat informasi yang siap berperan serta dalam semua aspek pembangunan.

4. Memiliki pengetahuan yang terkini, bukan yang sudah "basi".

5. Meningkatkan kemampuan berpikir.

6. Mengisi waktu luang.

Dalam belajar diperlukan suatu pemusatan perhatian agar apa yang dipelajari dapat dipahami. Sehingga siswa dapat melakukan sesuatu yang sebelumnya tidak dapat dilakukan (Junaidi Awang Besar \& Mohd Fuad Mat Jali, 2010).

\section{KESIMPULAN DAN SARAN}

\section{Kesimpulan}

Pelaksanaan kegiatan Pengabdian Kepada Masyarakat oleh Lembaga Penelitian dan Pengabdian Masyarakat (LPPM) Universitas Pamulang yang dilakukan oleh Mahasiswa/i program studi Manajemen telah berjalan dengan lancar dan mendapat sambutan hangat dari tempat pelaksanaan kegiatan ini yaitu Yayasan Islam Al-Akhyar kota depok. Harapan kami dengan pengabdian ini dapat membuka wawasan dari Yayasan Al-Akhyar kota depok yang akan menghadapi era globalisasi . sekaligus bahan kajian dan masukan bagi masyarakat (guru, orang tua peserta didik Yayasan Al-Akhyar kota depok) tersebut untuk dapat mengimplementasikannya dalam kehidupan sehari-hari, sehingga dapat membantu dan meningkatkan ekonomi dan keperibadian yang yang 
Loyalitas Kreativitas Aldi Masyarakat Kreatif
P-ISSN 2722-2101, E-ISSN 2722-4201

Program Studi Ekonomi Manajemen Universitas Pamulang Jurnal LOKABMAS Kreatif Vol.02,No.02.Juli 2021 Hal.58-61 Email:jurnalkreatif.manajemen@gmail.com akan sangat bermanfaat dalam kehidupan mereka pada masa yang akan datang. Dalam laporan kegiatan ini mungkin banyak kekurangan yang ada, untuk itu kami berharap masukan dan kritikan dalam rangka perbaikan untuk kegiatankegiatan pengabdian masyarakat dimasa yang akan datang. Semoga kegiatan pengabdian masyarakat ini dapat bermanfaat bagi masyarakat sekitar lingkungan Yayasan Islam Al-Akhyar Kota Depok.

\section{Saran}

Kegiatan pengabdaian ini akan memberikan manfaat yang banyak bagi masyarakat, maka dari itu, selanjutnya diperlukan:

1. Mengadakan penyuluhan dan pelatihan Serupa pada anak-anak agar meningkatkan minat membaca dan kreativitas pada anak dimasa pandemi Covid-19.

2. Menyediakan perpustakaan. Ketersediaan perpustakaan kecil akan membantu anak terbiasa akrab dengan buku hal tersebut juga membantu anak menyukai buku. Buku ditata sedemikian rupa sehingga menarik anak untuk senang membaca.

3. Membuat program wajib baca dalam keluarga. Di rumah, pada jam-jam tertentu anak dibiasakan untuk diterapkan wajib membaca buku, sehingga anak akan terbiasa untuk membaca buku.

\section{DAFTAR PUSTAKA}

Susanti, F., Jaswita, D. I., \& Mardiana, S. (2020).

PENGEMBANGAN

POTENSI

EKONOMI

KEWIRAUSAHAAN IBU RUMAH

TANGGA

DALAM

MENINGKATKAN

EKONOMI

MASYARAKAT KELURAHAN

CEMPAKA PUTIH

CIPUTAT. Jurnal Lokabmas Kreatif:

Loyalitas Kreatifitas Abdi Masyarakat

Kreatif, 1(1), 89-95.
Pasaribu, V. L. D., Susanti, F., \& Hartuti, E. T. K. (2019). Memotivasi Siswa dan Siswi SMK Letris Indonesia di Dalam Menentukan Pilihan Untuk Melanjutkan Pendidikan Atau Bekerja Setelah Lulus Sekolah. Jurnal Pengabdian Dharma Laksana, 1(2), 161-172.

Susanti, F., Ratnawati, W., \& ivan Jazwita, D. (2020). Literasi Digital Facebook dan Whatsapp terhadap Motivasi Belajar Generasi Milenial. Jurnal Lokabmas Kreatif: Loyalitas Kreatifitas Abdi Masyarakat Kreatif, 1(2), 35-40.

Susanti, F., Lisdawati, L., Andini, R., Setiawan, R., \& Ratnawati, W. (2020). Menanamkan Jiwa dan Semangat Kewirausahaan Persaingan Menghadapi di Era Globalisasi pada Guru dan Orangtua Murid Bimbingan Belajar Bimba Pamulang Tangerang Selatan. DEDIKASI PKM, 1(1), 95100.

Nurwita, N., Susanti, F., Permada, D. N. R., \& Oktrima, B. (2020). DAMPAK BURUK PEMAKAIAN MEDIA SOSIAL TERHADAP SEMANGAT DAN CAPAIAN BELAJAR SISWA SMP ARRAISIYAH PAMULANG". Jurnal Abdimas Tri Dharma Manajemen, 1(1), 66-76.

Susanti, F., Lisdawati, L., Hulasoh, E., Malik, C. D., \& Fadillah, F. (2021). PELATIHAN DAN PEMBENAHAN MANAJEMEN KEUANGAN DAN ADMINISTRASI PADA YAYASAN NURUL IMAN Kelurahan Ciater Serpong Kota Tangerang Selatan. Pro Bono Jurnal Pengabdian Kepada Masyarakat, 1(01). 
P-ISSN 2722-2101, E-ISSN 2722-4201

Loyalitas Kreativitas Program Studi Ekonomi Manajemen Universitas Pamulang Jurnal LOKABMAS Kreatif Vol.02,No.02.Juli 2021 Hal.58-61 Email:jurnalkreatif.manajemen@gmail.com

\section{FOTO DOKUMENTASI}
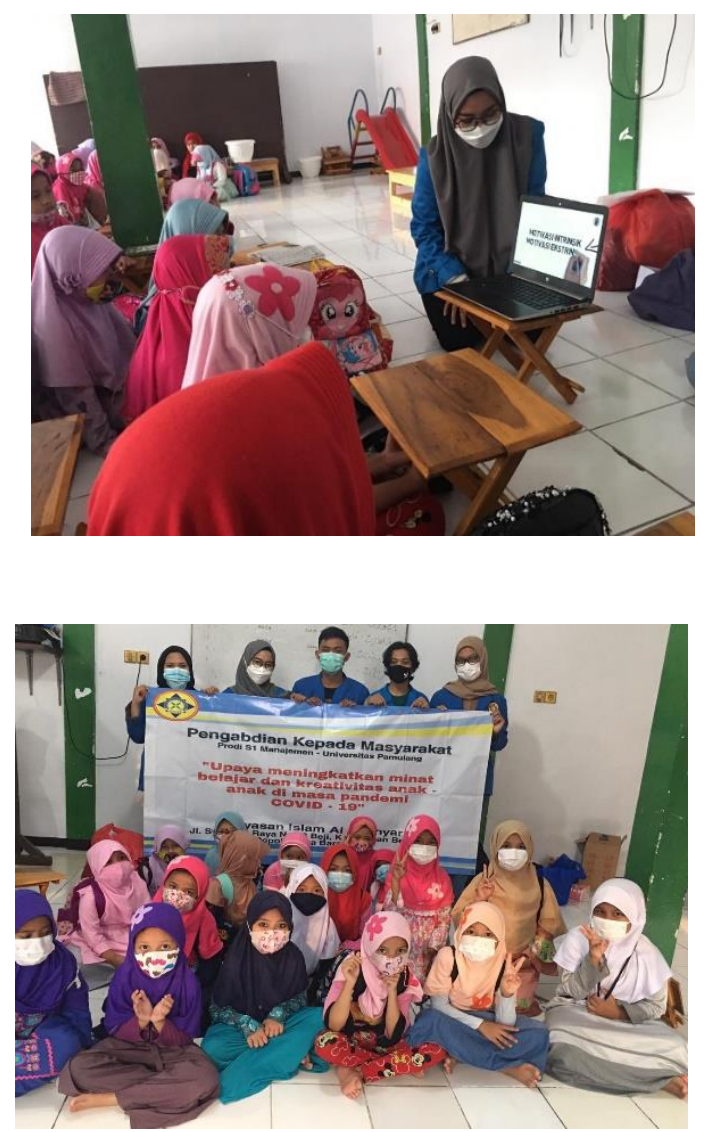